\title{
Applications of Mobile Learning and Transactional Distance Theory in the Context of Higher Education during COVID-19 Pandemic
}

\author{
Haifa F. Bin Mubayrik ${ }^{1}$ and Abdulah H. Alabbad ${ }^{2}$ \\ Educational Policies Department, College of Education, King Saud University, \\ Kingdom of Saudi Arabia \\ ${ }^{1}<$ hfm2007us4@gmail.com>, ${ }^{2}<$ aalabbad@KSU.EDU.SA>
}

KEYWORDS Coronavirus. Distance Program Nature. E-learning. Individual Learner Autonomy. Mobile Applications. Teacher-learner Dialogue

\begin{abstract}
Mobile learning, which can be performed through numerous applications that run on smartphones, personal digital assistants, and other devices, has played a major role in education, especially during under the restrictive conditions due to the COVID-19 pandemic. This paper is a review of literature of mobile learning efficiency in education. Some application of m-learning in education have shown extensive success. Mobile learning could meet with success in a suitable learning environment. The recently developed transactional distance theory focuses on three elements in the connection and involvement in the distance education environment, namely, the teacher, the student, and dialogue. The core of that theory is investigating the ways that the learner can progress to becoming a self-directed learner with the support of the teacher. Though there are advantages to m-learning, there are some disadvantages of m-learning such as technical, physical and health issues.
\end{abstract}

\section{INTRODUCTION}

In the twenty-first century, the explosion of information and communication technology has led to a significant growth in the potential uses of digital devices for many purposes in the world of work, and in formal and non-formal education (Basak et al. 2018).

Information and communication technologies have improved dramatically over the past few decades, and computers have become common and widespread. As a result, educators have begun to consider novel ways to utilise information technology. At first, computer-based education referred to the use of computers in education for all purposes (Tatli 2009), including progressing to online training and e-learning by the mid-1990s (Trelease 2016). E-learning provides students with a way to understand their course materials better through multimedia interactions. This led to sig-

Address for correspondence:

Haifa F. Bin Mubayrik

Professor,

Department of Educational Policies,

College of Education,

King Saud University, Riyadh,Saudi Arabia

PO Box 3680 - King Saud University

Unit No. 3

Riyadh 12372 - 7453 nificant development in teaching methods, which led to improved management of study at home and of independent instruction.

One of the most ubiquitous and dynamic novelties of recent developments in communication is the smartphone, which combines a mobile phone with a device that can also be used to communicate via email, conduct internet searches, and as a platform for specialised applications. The smartphone sector is one of the fastest-growing areas in the technology industry, and their impact on medicine (Ozdalga et al. 2012) and other fields has been quite extensive.

The use of the smartphone has enabled the use of digital learning to a greater extent, in the forms of electronic learning (e-learning), mobilebased learning (m-learning), and digital learning (dlearning) (Basak et al. 2018). M-learning is frequently viewed as a novel type of e-learning. M-learning is often considered to be a new step in the development of e-learning but one that lies within the limits of the former. M-learning does not simply refer to any online or internet-based e-learning but can include the concept of study at any place at any time without requiring any permanent connection to one or another physical network.

The advantages of m-learning include its simplicity, expense, flexibility, ease of use, and time- 
ly implementation. The devices used include mobile phones, tablet PCs, and portable computers. The key features of m-learning identified in this study are its ability to provide information that is “just in time, just enough, and just for me", learning that is located (either in the field or at the workplace), and its ability to be contextualised through mediation with peers and teachers. Mobile devices make this type of learning easier to access, but they are only tools for delivering the same learning that previously could only be achieved with a knowledgeable tutor working on site. Tutors are very expensive, but mobile technology can provide an individual learner with an equivalent high-quality education nearly for free (Lave and Wegner 1990).

Educational organisations in several nations throughout the world were temporarily shuttered due to social distancing measures and bans on mass assembly imposed during the COVID-19 pandemic. As governments throughout the world raced to fill the hole with online learning solutions, uncertainty about how long educational organisations will be closed has added to the complexity of their efforts (Chukwuemeka et al. 2021).

Research has shown that m-learning has positive effects on learning. M-learning has piqued the interest of academic disciplines all around the world, and the necessity to enrich this mode of education has emerged in the days leading up to COVID-19 (Matzavela and Alepis 2021). Furthermore, the so-called "network society" and organisations have recognised the importance of $\mathrm{m}$ learning, which was previously less demanding (Kazaishvili and Khmiadashvili 2020).

Recent research studies have shown that mlearning is capable of providing learners with opportunities to practice some subjects or learning English language skills on their smart mobile phones and tablet PCs (Zou and Li 2015). Huynh and Khatiwada (2021) described how one teacher used m-learning tools to make online teaching and learning more feasible and engaging. Asghar et al. (2021) discovered that pre-service teachers have easy access to mobile phones and the Internet.

This paper focuses on m-learning and the transactional learning theory and its relation to m-learning. Transactional Distance Theory (TDT) is a long-standing theory used mostly in distance education. When students are physically sepa- rated from their instructors and other students, they feel detached and isolated, according to the notion. Three important components were introduced, namely, dialogue, course structure and learner autonomy (Limtrairut and Marshall 2020).

\section{Objectives}

The aim of the study is to:

1. Review the nature of the mobile applications from the relevant sources.

2. Investigate the role of the new mobile applications in teaching in higher education.

3. Describe the Transactional Distance Theory in higher education.

4. Explore the relation between the transactional theory and mobile learning during the education process.

\section{Review Questions}

In general, this study attempts to find about Mobile Learning and Transactional Distance Theory in the context of higher education.

The proposed research will conduct a systematic review to determine the mobile applications and transactional distance theory in the context of higher education. The following questions will be addressed in the research.

1. How are the m-learning applications and Transactional Distance Theory used in the context of higher education?

2. What are the characteristics of the m-learning or Mobile Learning and Transactional Distance Theory in the context of higher education?

\section{MATERIAL AND METHODS}

\section{Search Strategy}

The researchers searched the literature for publications on the use of m-learning in higher education and educational applications in the scholarly, peer-reviewed journals, published between 2008 and 2021. The titles contain specific terminologies such as, "mobile applications, educational English applications or apps, educational applications or apps, higher education, and transactional learning theory", and in combination such as, "higher education and COVID-19,

Int J Edu Sci, 34(1-3): 1-10 (2021) 
transactional learning theory and mobile learning, mobile learning and higher education, mobile apps and English learning”. The titles and abstracts or entire manuscripts, if necessary were searched, the researchers found that most of the m-learning apps' results were more in learning English. In all, 150 articles were found. Papers that appeared outside of peer-reviewed journals, papers presented at conferences, and editorials were not included. After unrelated articles and works not written in English were also removed, a total of 51 papers were selected for the review (Fig. 1).

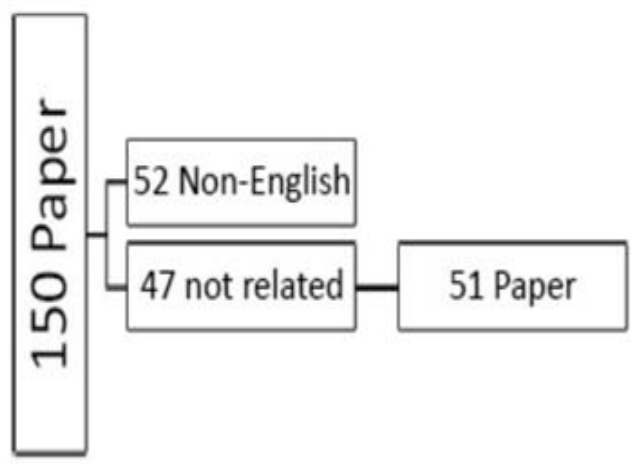

Fig. 1. Material and methods Source: Authors, 2021

\section{OBSERVATIONS AND DISCUSSION}

\section{Relationship between M-learning and E-learning}

According to Ozuorcun and Tabak (2012), elearning is the provision, via electronic media, of instructional resources through the internet, intranets, extranets, satellite broadcasting, audio/ video tape, interactive TV, and CD-ROM. M-learning derives from e-learning, and e-learning in turn derives from digital learning (d-learning).

Ozuorcun and Tabak (2012) and Kumar et al. (2018) illustrated the relationship between mlearning and e-learning by differentiating between the traditional educational environment. They divided the educational environment into traditional and distance environment. The e-learning is two types. They are online and m-learning. They both depend on technology. Some learning technologies, on the other hand, could be classified as both m-learning and e-learning.
Table 1: Relationship between m-learning and elearning

\begin{tabular}{lc}
\hline \multicolumn{2}{c}{ Educational environment types } \\
\hline Traditional education & Distance learning \\
\hline - & $\begin{array}{c}\text { Two types: E-learning (on } \\
\text { line and m-learning) and } \\
\text { distance learning }\end{array}$ \\
\hline
\end{tabular}

\section{M-learning Development}

The first tablet that had a truly global influence was the first-generation Apple iPad, which was formally released in 2010. The tablet was operated intuitively, using the fingers, could easily be connected to the internet, and could run a large number of applications offered by Apple on its online App Store. Until the release of the fourthgeneration iPad in November 2013, it underwent very rapid technical advances. All of Apple's mobile devices feature a relatively closed operating system, which is particularly used by large numbers of users due to its simplicity speed, and user friendliness. In 2007, under the leadership of Google, rival companies launched their open Android operating system for use on mobile devices, and it eventually became the platform used on the smartphones made by HTC, LG, Samsung, and Lenovo, among others. The Android operating system reported significant expansion, reaching fifty-nine percent of the market share for mobile devices in early 2012, and it went on to dominate the market, reaching an eighty percent share in 2013. The Android Market, where applications for this operating system were sold, was opened in October 2008, and the Google Music service was likewise expanded. The two services merged in 2012, creating Google Play (Kopecký and Hejsek 2015).

\section{Layout}

A direct consequence of the rapid technological growth witnessed in recent times is the digitalisation of education and educational services. Mobile devices can be used effectively in the classroom, not only to encourage and improve students' skills with electronic devices but also to enhance their engagement and motivation in different learning activities. This will, above all, adequately prepare them for the world outside of

Int J Edu Sci, 34(1-3): 1-10 (2021) 
school. It can also encourage learner autonomy and peer learning opportunities within the classroom by supplementing classroom activities through mobile application technology (Kappamaki 2020). To this end, there are many kinds of free applications that learners can download and use anywhere and at any time, independently. This creates many opportunities for learning and provides helpful tools for language learners to improve their language skills through these applications. However, if their network access is poor, language learners might not be able to use the mobile apps to their full advantage, and further, some applications may not be user-friendly and are varied (Tappoon 2020).

The main difference in the implementation between e-learning and m-learning is the inclusion of skills and limitations. Scholars agree that m-learning is e-learning, regardless of where and when it occurs (Alzaza and Yaakub 2011).

This paper explores m-learning within the field of learning applications used commonly in learning and languages learning, because it is the most common approach. This study investigates the importance of m-learning applications in higher education for self-learning.

\section{M-learning and Massive Open Online Courses}

The effects of wide-open online courses on teaching and learning process have been studied in many contexts (Viswanathan 2012). Modern elearning patterns are dominated by massive open online courses (MOOCs), especially in the form adopted by world-renowned universities, such as Stanford (MOOC Coursera), Harvard (MOOC Edx), MIT, Yale, and others. MOOCs are courses designed for an unlimited number of students who interact through the Internet. This model is based on conventional MOOC LMS systems, where students have access to an online environment, attend virtual lectures and seminars, conduct assigned tasks, and so on. The capacity of the courses is not limited in principle, so thousands of students from all around the world can participate at once. MOOC courses are accessible from tablets and other mobile devices as well as desktop computers (Kopecki and Hejsek 2015).

The use of MOOCs is developing new pedagogy to support teachers and students alike. The advantages of m-learning have been well studied. Many MOOC providers quickly launched mobile applications for popular mobile operating systems and adapted their web pages to the screen size of mobile devices and the mode in which they are used to capture the m-learning trend and allow learners to use them more conveniently. MOOC providers are seeking to popularise their courses and related educational productions. They are expanding their accessible learning tools around the world and leveraging m-learning to encourage learners to participate more easily in learning activities, regardless of any constraints of time and place (Sun et al. 2015).

\section{M-learning: A Paradigm Shift}

M-learning is moving toward relying on elearning applications, another type of m-learning that makes it much easier for learners to approach the desired text and problem solve. Via the Internet and m-learning system, m-learning helps students to learn, collaborate, and exchange ideas. Many scholars have reported that students and teachers are committed to learning mobile technology in higher education. For example, the most attractive and simplest tool for learning such as learning foreign languages is m-learning. Some studies of mobile-assisted language learning articles discuss the importance of learning foreign languages in m-learning. Taking advantage of computer-assisted learning, m-learning can be helpful in cultural and language study in an online augmented reality environment using freehand gesture interaction. A vast number of videos, photos and tutorials in mobile apps are available for different languages and are a very useful and versatile language learning tool that can support and guide language learning. At present, foreign language institutes use the same techniques with their students and in their courses as well (Qureshi et al. 2020). Furthermore, Hossain et al. (2021) tried to discover how students reacted to m-learning tools as a result of the COVID-19 pandemic, indicating a greater proclivity to employ smart technologies and applications to cooperate online learning with mobile devices. In their survey, Biswas et al. (2020) used a questionnaire on 416 students from various Bangladeshi universities to learn about their perceptions about

Int J Edu Sci, 34(1-3): 1-10 (2021) 
utilising mobile phones as a learning system. The result of this study reveals that the majority of university students have a positive attitude toward m-learning. This research found that m-learning is particularly useful in filling up the study gaps during COVID-19.

The basic paradigms of when, where and how school education subjects can be delivered have changed. M-learning is a unique approach to learning that has changed it, and it is necessary to keep up with changes in the field and promote more effective ways of taking advantage of $\mathrm{m}$ learning (Rosman 2008). Hence, m-learning provided freedom of place and time for students, improving the instruction they encountered and facilitating one-on-one learning that takes into account individual differences (Kim et al. 2006). Additionally, handheld mobile computing devices allow for non-specific location exploration events, such as field trips, that do not require students to lose the ability to take electronic notes and retrieve information of various kinds, which could be instructional guidance and other courserelated applications (Rosman 2008) must be modified in response to this major shift.

Ad hoc communication and informal contact between students are enabled through a switch to m-learning from stationary learning. The teacher-student partnership, expectations, evaluations, transparency, and conventional regional boundaries are fundamental problems in relation to this kind of change that must be dealt with by state and local school boards. Properly facilitated, if students are offered access to virtual classrooms on their mobile devices, m-learning can aid learners profoundly, and relative to conventional classroom approaches, teachers will be able to invest more time on course implementation and followup (Rosman 2008). Moreover, through online teaching, teachers can learn about and adapt to evolving environments, when and where it is necessary, so that they can keep up with this changing phenomenon and continue to develop current educational topics for future education (Kim et al. 2006) to effectively promote m-learning.

\section{Teacher-Student Relationships in M-learning}

The teacher-student relationship has always been important and will continue to be so. A "mixed learning” approach, an intelligent mixture of e- learning and instructor-led instruction, is what will ultimately occur in the m-learning model. Links to multimedia learning resources and all the material available on the Internet is available to the student in this format. The instructor serves as a guide and shows students how best to obtain the knowledge they need to use m-learning tools. Constructivism is the dominant pedagogy used in online learning. Teachers and students also need to understand the essence of social interactions. The quality of the interaction and communication is determinant for successful teaching in the m-learning environment and maintaining communicative competence, which involves the sharing of information, expertise, experience, and skills development. As they build social spaces for reflective learning by students, teachers must consider the dynamic relationships among cognitive activities, socio-emotional dimensions of learning, and the social meaning of learning. Online learning, especially m-learning, is necessarily different from the conventional teaching approach guided by the teacher in traditional face-to-face instruction (Sharma and Kitchens 2004).

Another theory is the Transactional Distance Theory (TDL), which is discussed above.

\section{Transactional Distance Theory}

TDL or Transactional Distance Theory, proposed by Michael Moore in the early 1970s, is an important theory of distance education, and it provides a broad structure for distance education pedagogy and allows for the generation of an almost infinite number of study hypotheses (Giossos et al. 2009).

The transaction in distance learning referred to in the name of the theory refers to the contact that takes place through the distribution medium between learners and instructors. Distance education in any program can be described through TDL in reference to the transactional distance between the teacher and the students. Such descriptions are founded on two elements, that is, dialog and structure (Braxton 1999).

The study of distance education has accepted TDL theory as a seminal orientation, which offers a broad foundation for distance learning pedagogy (Kang and Gyorke 2008). In this theory, it is suggested that pedagogy, not the physical or temporal distance separating teacher and

Int J Edu Sci, 34(1-3): 1-10 (2021) 
learner, is the most significant influence on distance education (Gorsky and Caspi 2005). TDL accounts for the variety of educational approaches currently in use in higher education, that is, face-to-face, mixed, or entirely online (Larkin and Jamieson-Proctor 2015).

Three main interrelated factors affect transactional distance, that is, the nature of the program, the dialog between teacher and learner (and ultimately between learners), and the level of autonomy of the individual learner (Larkin and JamiesonProctor 2015). The omission of one of these variables can result in an absence of TD, implying that there can be no educational transaction (Moore and Kearsley cited in Kang and Gyorke 2008).

Dialog is used to refer to the interplay between the words and acts of the instructor and the learner as one offers guidance and the other responds to it. Such interactions are important for the development of dialog, but they are not synonymous with dialog, which has been described as a positive interaction in "which each party is purposeful, constructive and valued”. Moore (1993) suggests that the medium of communication is a key component in deciding what types of dialogs can occur, and it is possible to increase dialog between learners and their teachers by manipulating the medium of communication and thus decreasing the transactional gap. Structure refers to the degree to which the learning needs of particular students can be described by an educational course or an entire program. According to Moore (1993), a framework "expresses the rigidity or flexibility of the educational goals, teaching strategies and assessment methods of the program.” The way in which these elements are constructed dictates the consistency of the structure (Moore cited in Larkin and Jamieson-Proctor 2015).

\section{Viral Mobile Technologies}

There are many types of mobile technology. Among these are Wi-Fi technology (enabling wireless networks that uses two-way communication along radio waves), Bluetooth technology (a type of wireless personal area network or PAN, which provides a way to link and communicate information over an unlicensed short-range radio frequency band between Bluetooth-enabled devices such as mobile phones, laptops, PCs, printers, digital cameras, etc.), WiMax network technolo- gy, and broadband wireless network (a wireless broadband technology that allows for long-distance communication), and cell phone network technology (a portable electronic device used for wireless or long-range mobile communication) (Jacob and Issac 2008).

Other uses of wireless mobile phones include the following:

1. Web-enabled cellular communication, which is similar to mobile phones, but it has the ability to access the internet. As a device for connecting to the Internet through a cell phone, it uses wireless application protocol (WAP). This type of device can be called a WAP phone.

2. Wireless handset is a kind of mobile phone that offers additional functions for a communications device, such as voice-activated dialling, a WAP interface, and two-way text messaging.

3. Smartphone is a device incorporating a computer and a cell phone (Kim et al. 2006).

\section{Mobile Phone Learning Applications}

Tappoon (2020) described the selection of mobile applications by students at a Thai Institute. These included well-known dictionary applications (like Oxford, Merriam Webster, and Google Translate), YouTube channels (Loukgolf's English Room and music videos with lyrics), and other applications found were more general and discursive (BBC Learning English TED Talk). Others included those used in the medical field like ell Scope Lite, Digital Otoscope, FireflyPro Mobile and iScope (Wallace and Kanegaonkar 2020).

\section{Mobile and Language Learning in Learning Application}

Online learning, especially m-learning, is different from conventional instruction dictated by a traditional face-to-face teacher. Many students aspire to develop their English learning skills with mobile-assisted language learning, which facilitates language learning through mobile devices. By comparison to reading and writing, where students are given time to respond, they typically struggle with listening and speaking due to the

Int J Edu Sci, 34(1-3): 1-10 (2021) 
rapid and immediate nature of most conversation (Al-Zahrani 2015).

Researchers have shown an interest in exploring mobile use in language learning. Al-Zahrani (2015) studied the use of the mobile application WhatsApp for enhancing English writing, and he found that it improves the English writing of university students. Andersson and Olsson (2018) reviewed a number of research papers, which indicated that students could understand written text better and helped them organise their thoughts in sequence. It also was seen to immediately motivate the students. Third, students may benefit from peer-editing reviews through collaborative work using mobile applications. Abu-Ayfah (2020) investigated the perceptions of the use of the Telegram application for English language learning among students in the department of English and Translation at Tibah University in Al-Medina Al-Manwarah in Saudi Arabia. It was found that a majority of EFL students viewed Telegram as a useful tool for learning English. The findings of this study can contribute to the development of learning techniques in higher education in Saudi Arabia. Morgana (2018) found a positive impact for the performance of speaking tasks on the motivation of students and improvements in the product of writing tasks when mediated by technology. Furthermore, that study showed that the use of the iPad had a positive effect on teachers' design of speaking and writing tasks. Al-Emran (2020) discussed the advantages of m-learning and found that it helps students improve their conversational and technical skills and find answers to their questions, encourages the exchange of information and cooperation, and improves their learning outcomes. Through m-learning, educators can also personalise their instructions and encourage learners to self-regulate their learning. Guo et al. (2020) found positive attitudes toward mobile-supported English among rural Chinese school students, who mainly used smartphones, followed by portable electronic dictionaries, tablets, and laptops in informal English learning.

Finally, Ahn (2021) discussed Korean college students studying EFL, who perceived that the ASELL app for English language learning to have usefulness, convenience, positive social impact, the ability to provide pleasure, and a tendency to develop their learning self-management. Howev- er, some issues may arise that would hinder English language learning through m-learning. According to Alfallaj and Alfallaj (2020), the teachers' inability to creatively incorporate m-learning technology into the learning process made this intervention more of a superimposed compulsion than a pleasant instrument that could improve the learning experience.

In addition to constraints on screen size and to keyboard constraints, m-learning requires academic, social and political leadership skills critical for the successful adoption of emerging technology to be developed, including several factors that go beyond the classroom (Burston 2015).

Walsh (2015) summarised these as follows. Mobile devices can be used for multiple purposes. As a result, students might be distracted while in the learning environment. High users of online learning might take their learning back home, which might affect their family lives. Other pedagogical challenges and ethical issues existed in m-learning as well.

Wireless technologies such as Wi-Fi, Bluetooth, and Zigbee have been popular choices for last-mile connectivity, as they can significantly restrict the distance between the communicating entities. Types of connectivity that are cost effective, low power, and wireless, such as the LoRa (long-range) standard and the low power wide area network technology are being studied (Dasiga et al. 2020). In addition, wireless ISPs (WISPs), which rely on point-to-point wireless backhaul infrastructure to provide connectivity using cheap commodity wireless hardware, are the most viable and cost-effective strategy for providing lastmile connectivity. WISPs link millions of rural users worldwide and use cheap hardware for commodity networking and fragile tree-like network topologies to keep costs down (Saleem et al. 2020). Last-mile networks are highly restricted compared to data centre networks, which are comparatively over-engineered and ultimately take responsibility for the performance problems that affect the user experience. WISPs will ultimately facilitate and spread m-learning use.

\section{M-learning and the Pandemic}

The global pandemic has driven most people worldwide into quarantine. Many cities have turned into phantoms, and the effects can also be

Int J Edu Sci, 34(1-3): 1-10 (2021) 
seen in schools, colleges and universities (Dhawan 2020). Students' fear can also influence their adoption of technology, as the responses to the pandemic have prompted universities, colleges and schools to introduce distance learning to minimise the negative effects of the pandemic and preserve student learning. After the spread COVID-19 was declared a pandemic, students encountered the effects of prejudice, loss, and numerous other psychosocial problems. The lockdown also had an effect on students' fear. Educational institutions were forced to suspend their communication study and teaching activities, and the need for elearning became more urgent. Students' fear may manifest itself as fear of risk-taking, fear of failure, fear of missing out, and fear of insecurity (Ahorsu et al. cited in Akour et al. 2021).

The current state of education allows no choice rather than m-learning, led by the pandemic to migrate to an online pedagogy mode. This crisis forces new technologies to be embraced by organisations that were previously resistant (Dhawan 2020). This entails, numerous novel opportunities for creative approaches to education that can be adopted by schools around the world amid the challenges caused by the pandemic to the education sector (Sintema 2020).

Some published papers have shown that students did not prefer e-teaching over face-to-face teaching. Administrations and faculties should take steps to enhance e-teaching for better learning during lockdown (Abbasi et al. 2020).

The pandemic has indicated a possibly lucrative side of teaching and learning online. A large number of students from all over the world can participate in m-learning.

All institutions must remove multiple choices for online pedagogical methods and strive to use technology more effectively. To appreciate the desperate need evoked by the current situation, many universities around the world have completely digitised their operations (Dhawan 2020). For example, the students in the study reported by Abbasi et al. (2020) did not prefer e-teaching to face-to-face teaching during the lockdown situation. Administration and faculty members should take the necessary measures to improve e-teaching and enable better learning during lockdown.

A range of studies have indicated that there are numerous opportunities for creative approaches to education that can be adopted by schools around the world amid the challenges posed by pandemic to the education sector (Sintema 2020). However, m-learning has some drawbacks, such as a lack of technology and internet access, technical problems, speed, connectivity, memory and file format support concerns, the potential of distraction, and the negative consequences of mobile phone use on physical and mental health (Jayaseelan et al. 2020).

M-learning offers a rare platform for teachers and students in different learning environments. One unique feature of this learning mode is that it increases student flexibility. However, it requires new pedagogies and new approaches in course delivery (Lave and Wegner 1990). If adequately supported, m-learning cam benefit learners tremendously by bringing them virtual classrooms through their mobile devices. Ultimately, teachers will spend more time on course delivery and follow-up than is done in traditional methods in classrooms. Teachers need to have a rich learning platform and atmosphere, which in turn leads to greater learning efficiency.

To keep up with these changes phenomena and to continue to effectively facilitate m-learning, it is imperative that online teachers investigate and adapt to changing environments, when and where appropriate. Adaptive mobile learning technologies will be of particular use to those who have traditionally pursued distance learning methods. Although the inherently portable and mobile nature of these strategies makes them highly useful for various interactive and dynamic activities, the limitations of using a small screen, potential limitations to bandwidth, and awkward methods of input cannot suit everyone. One must be careful not to expect too much from m-learning technologies, as many other newly emerging technologies were burdened with unsustainable expectations. However, adaptive m-learning technologies, if used sensibly, can revolutionise distance education by bringing concepts to reality anytime and anywhere. M-learning is not therefore a supplement for conventional e-learning. It is instead a better addition to it. Mobile computing makes sense when used in a typical e-learning environment where no other tools are available for computer-aided computing. An integration of e-learning and m-learning would be the ideal means of implementing both. This can allow students to use a desktop computer at home or a mobile phone when on the road.

Int J Edu Sci, 34(1-3): 1-10 (2021) 
TDL is a recently developed perspective on distance education. It emphasises the learner-dialog-structure relationship. These three elements must be taking into consideration together. The aim of the theory is to create a motivated and safe learning environment with a teacher while learning. As has been recognised, learning in the absence of the teacher may cause anxiety and confusion among students. The application of this theory may limit such factors. This means that the learner is a self-directed learner.

\section{CONCLUSION}

M-learning has many advantages in higher education. However, there are some disadvantages of m-learning. One of them is the lack of technology and Internet access, technical issues, speed, connectivity, memory, and file format support. Other effects are on physical and mental health.

\section{RECOMMENDATIONS}

Future research may seek to investigate the guidelines and policies that must be put in place to ensure that m-learning is successfully adopted. Such policies enable the development of an m-learning environment. Future research may analyse the technical capabilities of various wireless technologies and determine their suitability to the language environment for m-learning among college students. This could then lead to the development of an ideal device that is adaptable to any m-learning environment, including educational institutions and the business environment. More generally, the researchers expect that further study will help construct an improved theoretical context for understanding the role of these emerging forms of technology and their effects for improving educational standards in language learning.

\section{ACKNOWLEDGMENT}

The authors thank the Deanship of Scientific Research and RSSU at King Saud University for their technical support.

\section{REFERENCES}

Abbasi S, Ayoob T, Malik A, Memon SI 2020. Perceptions of students regarding e-learning during Covid-19 at a private medical college. Pak J Med Sci, 36(COVID19S4): S57-S61.

Abu-Ayfah ZA 2020. Telegram App in learning English: EFL students’ perceptions. Engl Lang Teach, 13(1): 51-62.

Akour I, Alshurideh M, Al Kurdi B, Al Ali A, Salloum S 2021. Using machine learning algorithms to predict People's intention to use mobile learning platforms during the COVID-19 pandemic: Machine learning approach. JMIR Med Educ, 7(1): e24032.

Ahn S 2021. Korean EFL college students' acceptance of Smartphone Applications for English language learning. In: CALL Theory Applications for Online TESOL Education. Hershey, PA, USA: IGI Global, pp. 100126.

Al-Emran M 2020. Mobile learning during the era of COVID-19. Rev Virtual Univ Católica Norte, 61: 1-2.

Al-Zahrani AS 2015. Smartphones Wandering At the Mall: A Case Study Investigating the Use of Smartphones on English Oral Learning Skills in a Collaborative Mobile-Assisted

Alfallaj FSS, Alfallaj F 2020. Technology in Saudi EFL undergraduate classrooms: Learning tool or weapon of distraction. The Asian Esp J, 16(4): 97-115.

Andersson E, Olsson J 2018. Examining the Use of Mobile Apps for Developing Writing in English Language Learning. Seweden: Digitala Vetenskapliga Arkivet.

Asghar MZ, Barberà E, Younas I 2021. Mobile learning technology readiness and acceptance among pre-service teachers in Pakistan during the COVID-19 pandemic. Knowledge Management \& E-Learning, 13(1): 83-101.

Alzaza NS, Yaakub AR 2011. Students' awareness and requirements of mobile learning services in the higher education environment. Am J Econ Bus Admin, 3(1): 95-100.

Biswas B, Roy SK, Roy F 2020. Students perception of mobile learning during COVID-19 in Bangladesh: University student perspective. Aquademia, 4(2): ep20023.

Braxton, SN 1999. Empirical Comparison of Technical and Non-Technical Distance Education Courses to Derive a Refined Transactional Distance Theory as the Framework for a Utilization-Focused Evaluation Tool. Doctoral Dissertation, Unpublished. USA: George Washington University.

Burston J 2015. Review of mobile learning: Languages, literacies, and cultures. Lang Learn Technol, 19(2): 44-49.

Chukwuemeka EJ, Dominic S, Kareem MA, Mailafia IA 2021. Redesigning educational delivery systems: The needs and options for continuous learning during the Coronavirus (COVID-19) pandemic in Nigeria. Contemporary Educational Technology, 13(1): ep292.

Dasiga S, Bhatia AAR, Bhirangi A, Siddiqua A 2020. LoRa for the Last Mile Connectivity in IoT. In: $9^{\text {th }}$ International Conference System Modeling and Advancement in Research Trends (SMART). Moradabad, India, 4-5 December, 2020, pp. 195-200.

Dhawan S 2020. Online learning: A panacea in the time of COVID-19 crisis. J Educ Technol Syst, 49(1): 522.

Giossos Y, Koutsouba M, Lionarakis A, Skavantzos K 2009. Reconsidering Moore's transactional distance theory. Eur J Open Distance E-Learning, 2: 1-6.

Int J Edu Sci, 34(1-3): 1-10 (2021) 
Guo J, Huang F, Lou Y, Chen S 2020. Students’ perceptions of using mobile technologies in informal English learning during the COVID-19 epidemic: A study in Chinese rural secondary schools. J Pedagog Res, 4(4): 475-483.

Hossain SFA, Shan X, Nurunnabi M, Tushar H, Mohsin AKM, Ahsan FT 2021.Opportunities and challenges of m-learning during the COVID-19 pandemic: A mixed methodology approach. In: Jingyuan Zhao, Joseph Richards (Eds.): E-Collaboration Technologies and Strategies for Competitive Advantage Amid Challenging Times. Hershey, PA, USA: IGI Global, pp. 210-227.

Huynh MQ, Khatiwada E 2021. Online teaching with mlearning tools in the midst of Covid-19: A reflection through action research. Issues in Informing Science and Information Technology, 18: 173-193.

Jacob SM, Issac B 2008. Mobile technologies and its impact-an analysis in higher education context. Int J Interact Mob Technol, 2(1): 10-18.

Jayaseelan R, Brindha MD, Kadeswaran S 2020. -learning among medical students, before and during Covid-19 lockdown. In: Zaheda Begum Shaik, Beena. Kumari. (Eds.): Covid 19 and Its Impact by Lockdown. Tamil Nadu: ESN Publications, pp. 35- 45.

Kang H, Gyorke AS 2008. Rethinking distance learning activities: A comparison of transactional distance theory and activity theory. Open Learn J Open Distance eLearning, 23(3): 203-214.

Kazaishvili A, Khmiadashvili L 2020. Nurturing M-Learning for Professional Development Through Online Digital Communicational Channels During COVID-19 Pandemic. In: International Conference on Reliability and Statistics in Transportation and Communication. Riga, Latvia, 14-17 October 2020, pp. 868-876.

Kim SH, Mims C, Holmes KP 2006. An introduction to current trends and benefits of mobile wireless technology use in higher education. AACE $J, 14(1)$ : 77-100.

Kopecki K, Hejsek L 2015. Mobile touch devices as an effective tool of m-learning and e-learning. Proceedings of the INTED, pp. 7934-7936.

Kumar Basak S, Wotto M, Belanger P 2018. e-learning, mlearning, and d-learning: Conceptual definition and comparative analysis. E-learn Digit Media, 15(4): 191-216.

Larkin K, Jamieson-Proctor R 2015. Using transactional distance theory to redesign an online mathematics education course for pre-service primary teachers. Math Teach Educ Dev J, 17(1): 44

Lave J, Wenger E 1990. Situated Learning: Legitimate Peripheral Participation. Cambridge, UK: Cambridge University Press.

Limtrairut P, Marshall S 2020. A New Design Guideline for Mobile Learning Application: Transactional Distance Perspective. In: 2020 IEEE $9^{\text {th }}$ Global Conference on Consumer Electronics (GCCE), 12-15 October, IEEE, Kyoto, Japan, pp. 610-614.
Matzavela V, Alepis E 2021. M-learning in the COVID-19 era: Physical vs digital class. Education and Information Technologies, 1-21 https://doi.org/10.1007/s1063 9-021-10572-6

Morgana V 2018. The iPad and the Development of Speaking and Writing in the Secondary EFL Classroom. Doctoral Dissertation. Milton Keynes, UK: The Open University.

Ozdalga E, Ozdalga A, Ahuja N 2012. The smartphone in medicine: A review of current and potential use among physicians and students. J Med Internet Res, 14(5): e128.

Ozuorcun NC, Tabak F 2012. Is m-learning versus e-learning or are they supporting each other? Procedia-Social and Behavioral Sciences, 46: 299-305.

Rosman P 2008. M-learning as a Paradigm of a New Forms in Education, 11(1): 119-125. From <200801.indd (ekonomie-management.cz) $>$ (Retrieved on 7 December 2021).

Saleem B, Schmitt P, Chen J, Raghavan B 2020. Beyond the trees: Resilient multipath for last-mile WISP networks. arXiv preprint arXiv: 2002. 12473.

Sharma SK, Kitchens FL 2004. Web services architecture for m-learning. Electronic Journal of e-Learning, 2(1): 203-216.

Sintema EJ 2020. E-learning and smart revision portal for Zambian primary and secondary school learners: A digitalized virtual classroom in the COVID-19 era and beyond. Aquademia, 4(2): ep20017.

Sun G, Cui T, Yong J, Shen J, Chen S 2015. MLaaS: A cloudbased system for delivering adaptive micro learning in mobile MOOC learning. IEEE Trans Serv Comput, 11(2): 292-305.

Tappoon A 2020. A selection of mobile applications in learning English between high and low proficient EFL learners in a Thai institute. The $N$ Engl Teach, 14(2): 64.

Tatli Z 2009. Computer-based education: online learning and teaching facilities. Energy Educ Sci Technol Part B, 1: $171-181$.

Trelease RB 2016. From chalkboard, slides, and paper to e learning: how computing technologies have transformed anatomical sciences education. Anat Sci Educ, 9(6): 583-602.

Viswanathan R 2012. Teaching and learning through MOOC. Front Lang Teach, 3(1): 32-40.

Wallace J, Kanegaonkar R 2020. The role of smartphone applications in clinical practice: A review. The Journal of Laryngology \& Otology, 134(2): 96-103.

Walsh K 2015. Mobile learning in medical education. Ethiop J Health Sci, 25(4): 363-366.

Zou B, Li J 2015. Exploring mobile apps for English language teaching and learning. Critical CALL, 564.

Paper received for publication in March, 2021

Paper accepted for publication in August, 2021

Int J Edu Sci, 34(1-3): 1-10 (2021) 